\title{
Enraizamento e morfo-anatomia de estacas caulinares de Odontonema strictum kuntze (Acanthaceae)
}

\author{
KATIA CHRISTINA ZUFFELLATO-RIBAS", MARIA REGINA TORRES BOEGER', CLEUSA BONA', \\ ELISÂNGELA DA GRAÇA BOENO PAES ${ }^{2}$, ALEX CAETANO PIMENTA ${ }^{3}$ e ELIANA TIEMI MASUDA ${ }^{4}$
}

\begin{abstract}
RESUMO
Odontonema strictum Kuntze é uma espécie ornamental bastante utilizada no Brasil, cultivada em renques ou isoladamente, devido a coloração vermelha de suas inflorescências e seu porte arbustivo, podendo atingir cerca de dois metros de altura. O objetivo deste trabalho foi estudar o enraizamento e a morfoanatomia de estacas herbáceas de $O$. strictum plantadas em tubetes de enraizamento, utilizando vermiculita de granulometria fina e pó de casca de coco como substratos. $\mathrm{O}$ experimento foi conduzido em casade-vegetação na Universidade Federal do Paraná, em Curitiba - PR. As estacas foram preparadas com um comprimento de $12 \mathrm{~cm}$ e duas folhas cortadas pela metade, na porção apical. Estas foram distribuídas em quatro parcelas com 10 estacas, num delineamento inteiramente casualizado. Após 44 dias da instalação do experimento, o enraizamento foi de $100 \%$ nos dois substratos estudados. O substrato vermiculita apresentou o maior número de raízes por estaca $(22,49$ raízes), enquanto o pó de casca de coco apresentou a maior média de comprimento das cinco maiores raízes por estaca $(11,67 \mathrm{~cm})$. Estruturalmente, as estacas de $O$. strictum se caracterizam por apresentar epiderme unisseriada, com paredes pouco espessadas; córtex composto de colênquima, parênquima e endoderme com estrias de Caspary; cilindro central em estrutura secundária, com periciclo apresentando grupos isolados de fibras, câmbio ativo e medula parenquimática. A região provável de origem das raízes adventícias é na periferia do floema. Os resultados indicam que esta espécie pode ser considerada de fácil enraizamento, não sendo necessária a aplicação de fitorreguladores.
\end{abstract}

As características anatômicas das estacas facilitam a formação de raízes adventícias.

Palavras-chave: odontonema, estaquia, substratos, anatomia caulinar, primórdios radiciais.

ABSTRACT
Rooting and morpho-anatomy of Odontonema
strictum kuntze (Acanthaceae) stem cuttings
Odontonema strictum Kuntze, a commonly cultivated
shrub in Brazil, has red flowers grouped in inflorescences
and can reach two meters high. The objective of this work
was to study the root formation and morpho-anatomy
of herbaceous cuttings of Odontonema strictum. The
cuttings were planted in conical polyethylene container
with vermiculite of fine granulometry and coconut coat
powder. The experiment was conducted in a greenhouse
at the Federal University of Paraná, Curitiba, Brazil. The
cuttings were 12 cm long with two leaves cut by half in
the apical portion. The experimental design used was a
completely randomized with 4 replications of 10 cuttings
each one. After 44 days, the root formation was $100 \%$ on
the two studied growing media. The vermiculite presented
the higher number of roots per cutting (22,49 roots) while
the coconut coat powder presented the higher average of
root size per cutting (11,67 cm). Anatomically, the cuttings
of $O$. strictum presented unisseriate epidermis, with thick
walls; cortex composed by collenchyma, parenchyma,
and endodermis with casparian strips; central cylinder in
secondary state of growth, having pericycle with isolated
groups of fibers, active cambium and medular parenchyma.
The probable origin of adventitious roots is the peripheral

\footnotetext{
1 Bióloga, Doutora, Professora Adjunta, Departamento de Botânica, Universidade Federal do Paraná (UFPR), Caixa Postal 19031, 81531-970 Curitiba (PR).
E-mail: kazu@ufpr.br
${ }^{2}$ Engenheira Agrônoma, Mestre em Agronomia - Produção Vegetal, Departamento de Fitotecnia e Fitossanitarismo, UFPR, Caixa Postal 19061, 80035-05

'Bióloga, Doutora, Professora Adjunta, Departamento de Botânica, Universidade Federal do Paraná (UFPR), Caixa Postal 19031, $81531-970$ Curitiba (PR).
E-mail: kazu@ufpr.br
${ }^{2}$ Engenheira Agrônoma, Mestre em Agronomia - Produção Vegetal, Departamento de Fitotecnia e Fitossanitarismo, UFPR, Caixa Postal 19061, 80035-05

Bióloga, Doutora, Professora Adjunta, Departamento de Botânica, Universidade Federal do Paraná (UFPR), Caixa Postal 19031, $81531-970$ Curitiba (PR).
E-mail: kazu@ufpr.br
${ }^{2}$ Engenheira Agrônoma, Mestre em Agronomia - Produção Vegetal, Departamento de Fitotecnia e Fitossanitarismo, UFPR, Caixa Postal 19061, 80035-05 Curitiba (PR).

${ }^{3}$ Biólogo, Mestre em Agronomia - Produção Vegetal, Departamento Fitotecnia e Fitossanitarismo, UFPR, Caixa Postal 19061, 80035-05 Curitiba (PR).

${ }^{3}$ Biólogo, Mestre em Agronomia - Produção Vegetal, Departamento Fitotecnia e
${ }^{4}$ Graduanda em Biologia, UFPR, Caixa Postal 19031, 81531-970 Curitiba (PR).
} 
phloem cells. The results indicate that the anatomical characteristics of the cuttings do not block the formation of adventitious roots, having no mechanical tissue on the cortex. This species has easy root formation and there is no need of plant growth regulator application.

Key words: Odontonema, cutting, growing media, stem anatomy, root primordium.

\section{INTRODUÇÃO}

Pertencente à Família Acanthaceae, Odontonema strictum Kuntze, comumente denominada de odontonema, é um arbusto semi-herbáceo, ereto, originário da América Central, que pode atingir de um a dois metros de altura. Possui inflorescências terminais firmes e vistosas, com numerosas flores pequenas, de coloração vermelha, muito duráveis, visitadas por abelhas jataí e beija-flores, florescendo na primavera e verão. É adequada para plantios a pleno sol ou a meia-sombra, junto a muros ou isolada. A propagação desta espécie pela técnica da estaquia é viável, principalmente quando os ramos são coletados no final do inverno (LORENZI \& SOUZA, 1999).

Segundo READ \& YANG (1991), a propagação vegetativa via estaquia é uma das técnicas mais utilizadas na área de plantas ornamentais, pois permite a obtenção de grande quantidade de mudas em curto período de tempo. Essa técnica possibilita a uniformidade e qualidade das mudas pela clonagem de genótipos selecionados de plantas matrizes produtivas e com boa sanidade, além de eliminar o período de juvenilidade (HARTMANN et al., 2002).

Entretanto, uma das dificuldades do sucesso do enraizamento é a característica anatômica do material vegetal a ser estudado. Dependendo da espécie, os tecidos mecânicos que a constituem podem atuar como uma barreira para a emissão dos primórdios radiciais, bloqueando sua formação (WHITE \& LOVELL, 1984).

$\mathrm{Na}$ literatura, há poucos trabalhos exploratórios sobre propagação vegetativa de $O$. strictum. Dessa forma, considerando a técnica da estaquia como a de maior viabilidade econômica para a formação de mudas, o presente trabalho teve por objetivo estudar o enraizamento e a estrutura anatômica de estacas herbáceas de Odontonema strictum.

\section{MATERIAL E MÉTODOS}

O presente experimento foi instalado em 29 de maio de 2002, sendo conduzido em casa-de-vegetação climatizada, com sistema de nebulização intermitente
( $90 \%$ UR e $24^{\circ} \mathrm{C}$ ), do Setor de Ciências Biológicas da Universidade Federal do Paraná, em Curitiba (PR).

Foram coletadas estacas caulinares herbáceas de Odontonema strictum, obtidas de brotações do ano, de plantas matrizes com, aproximadamente, quatro anos de idade, localizadas nos jardins dos arredores do Campus III da Universidade Federal do Paraná, numa latitude de $25^{\circ} 25^{\prime} \mathrm{S}$ e longitude $49^{\circ} 12^{\prime} \mathrm{W}$, a $930 \mathrm{~m}$ de altitude e clima tipo $\mathrm{Cfb}$, sem estação seca nitidamente definida, com um total de chuvas no mês mais seco superior a $30 \mathrm{~mm}$ e temperatura média do mês mais quente inferior a $22^{\circ} \mathrm{C}$, conforme classificação de Köppen.

As estacas foram preparadas com corte em bisel abaixo da última gema basal e corte reto acima da última gema apical, com comprimento aproximado de 12 $\mathrm{cm}$ e $0,6 \mathrm{~cm}$ de diâmetro, sendo mantidas duas folhas com sua área reduzida à metade na porção apical.

A desinfestação das estacas foi realizada por imersão total em hipoclorito de sódio a $0,5 \%$, durante cinco minutos, com posterior lavagem em água corrente, durante cinco minutos.

Em seguida, as estacas foram plantadas em tubetes de enraizamento com capacidade de $56 \mathrm{~cm}^{3}$ utilizandose, como substratos, vermiculita de granulometria fina e pó de casca de coco, sendo acondicionadas na casade-vegetação.

A vermiculita expandida utilizada foi proveniente da Empresa Eucatex e o pó de casca de coco, comercialmente conhecido por Coxim ${ }^{\circledR}$, da Empresa The Orchid House - Jardinagem, Paisagismo e Comércio Ltda.

Os dados foram analisados segundo um delineamento inteiramente casualizado com 2 tratamentos (2 substratos) e 4 repetições, sendo as unidades experimentais formadas por 10 estacas. As variâncias dos tratamentos foram testadas quanto à sua homogeneidade pelo teste de "Bartlett". As variáveis, cujas variâncias dos tratamentos se mostraram homogêneas, foram submetidas à análise de variância e, quando apresentaram diferenças significativas pelo teste $\mathrm{F}$, tiveram suas médias comparadas pelo teste de "Tukey" ao nível de 5\% de probabilidade. Quando as variâncias dos tratamentos se apresentaram heterogêneas, os dados foram transformados por raiz quadrada do valor, antes de serem submetidos à análise de variância.

A avaliação foi realizada 44 dias após a instalação do experimento, sendo estimados os seguintes parâmetros: porcentagem de estacas enraizadas, número de raízes por estaca, e comprimento das cinco maiores raízes por estaca $(\mathrm{cm})$. 
Para a análise anatômica, foram coletadas amostras da base das estacas plantadas no substrato vermiculita, nas regiões dos nós e dos entrenós, em intervalos (I) de três em três dias (I0, I1, I2, I3, I4, I5 e I6) totalizando 18 dias, desde a instalação do experimento, período em que foi observado, a olho nú o início da indução radicial.

As amostras foram fixadas em FAA 70 (formaldeído, ácido acético, etanol 70\%, 1:1:18 v/v) (JOHANSEN, 1940) e armazenadas em etanol 70\%. Posteriormente, foram desidratadas em série etílica e emblocadas em historresina (glicolmetacrilatoJB-4) segundo as técnicas de FEDER \& O'BRIEN (1968) e as indicações do fabricante. Os blocos foram seccionados em micrótomo rotativo e as secções coradas com azul de toluidina $0,05 \%$ em solução aquosa (O' BRIEN et al., 1965), e montadas em lâminas permanentes com resina sintética. Os grãos de amido foram identificados pela reação com Lugol (JOHANSEN, 1940), utilizando-se secções transversais de material fresco. As secções foram realizadas com auxílio de lâmina de barbear.

As fotomicrografias foram realizadas em microscópio Zeiss e as escalas aplicadas nas mesmas condições ópticas.

\section{RESULTADOS E DISCUSSÃO}

A porcentagem de enraizamento em estacas herbáceas de Odontonema strictum foi de 100\% para os dois substratos utilizados (Figura 1). Não houve a formação de calos nas estacas enraizadas; os primórdios radiciais surgiram diretamente da região basal das mesmas.

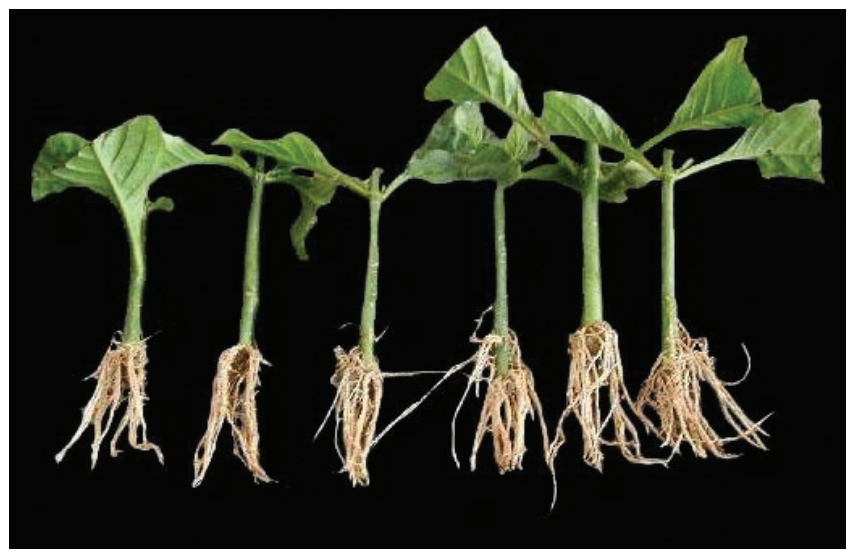

Figura 1. Aspecto geral das estacas de Odontonema strictum enraizadas no substrato vermiculita
Pela Tabela 1, verifica-se que o número de raízes por estaca foi maior no substrato vermiculita $(22,49)$, diferindo significativamente do pó de casca de coco $(16,10)$. Já para a média do comprimento das cinco maiores raízes por estaca, o substrato pó de casca de coco apresentou os maiores resultados $(11,67 \mathrm{~cm})$, diferindo significativamente da vermiculita $(8,82 \mathrm{~cm})$.

Uma vez que a porcentagem de enraizamento foi máxima nos dois substratos utilizados, as diferenças entre número e comprimento de raízes por estaca encontradas, devem ser levadas em conta somente considerando a disponibilidade de mão-de-obra para transplantio e aclimatação da muda. Se houver possibilidade de um rápido transplantio para saquinhos, para a etapa de aclimatação até posterior plantio definitivo, a vermiculita poderá ser o substrato ideal, já que produziu maior número de raízes por estaca. Porém, se após 44 dias houver uma demora neste procedimento, as longas raízes formadas no substrato pó de casca de coco deverão ser podadas antes de serem plantadas no saquinho, pois poderão enovelar-se não forem delicadamente acondicionadas.

Com a porcentagem de estacas de Odontonema strictum, enraizadas nos dois substratos utilizados, igual a $100 \%$, esta espécie pode ser considerada de fácil enraizamento. Assim, a estação do outono é uma época extremamente favorável para a indução radicial desta espécie, e não somente o inverno, conforme citado por LORENZI \& SOUZA (1999).

Com relação à estrutura morfo-anatômica das estacas herbáceas de Odontonema strictum, as secções transversais evidenciaram que o caule possui epiderme unisseriada, com estômatos e células epidérmicas com paredes periclinais externas espessas (Figs. 2 e 4). Em posição subepidérmica ocorre colênquima angular que é interrompido na região das câmaras sub-estomáticas por parênquima clorofiliano (Figura 4). Internamente ao colênquima, situa-se o parênquima cortical, composto por células isodiamétricas com pequenos espaços intercelulares e alguns idioblastos contendo mucilagem, amido e cristais prismáticos (Figuras 2 e 4).

A camada mais interna do córtex é a endoderme unisseriada, com estrias de Caspary (Figs. 5 e 6). O cilindro central é delimitado por agrupamentos de fibras pericíclicas, adjacentes ao floema primário (Figs. $2 \mathrm{e}$ 5). O caule encontra-se em estrutura secundária, com câmbio e xilema secundário contínuos e evidentes. A medula é parenquimática com células isodiamétricas, algumas com cristais, e pequenos espaços intercelulares (Figura 2). 
Tabela 1. Comparação das médias pelo teste de Tukey para porcentagem de estacas enraizadas, número de raízes por estaca e comprimento das cinco maiores raízes por estaca $(\mathrm{cm})$, de Odontonema strictum coletadas em maio/2002

\begin{tabular}{|l|c|c|c|}
\hline Tratamentos & Estacas Enraizadas & Raízes por estaca & $\begin{array}{c}\text { Comprimento das cinco maiores } \\
\text { raízes }\end{array}$ \\
\hline & $\%$ & $\mathrm{n}^{\circ}$ & $\mathrm{cm}$ \\
\hline Vermiculita & $100,00 \mathrm{~A}$ & $22,49 \mathrm{a}$ & $8,82 \mathrm{~b}$ \\
\hline Pó de casca de coco & $100,00 \mathrm{~A}$ & $16,10 \mathrm{~b}$ & $11,67 \mathrm{a}$ \\
\hline Coeficiente de Variação (\%) & - & 9,99 & 2,09 \\
\hline
\end{tabular}

Médias seguidas pela mesma letra na coluna não diferem significativamente pelo teste de Tukey a $5 \%$ de probabilidade.
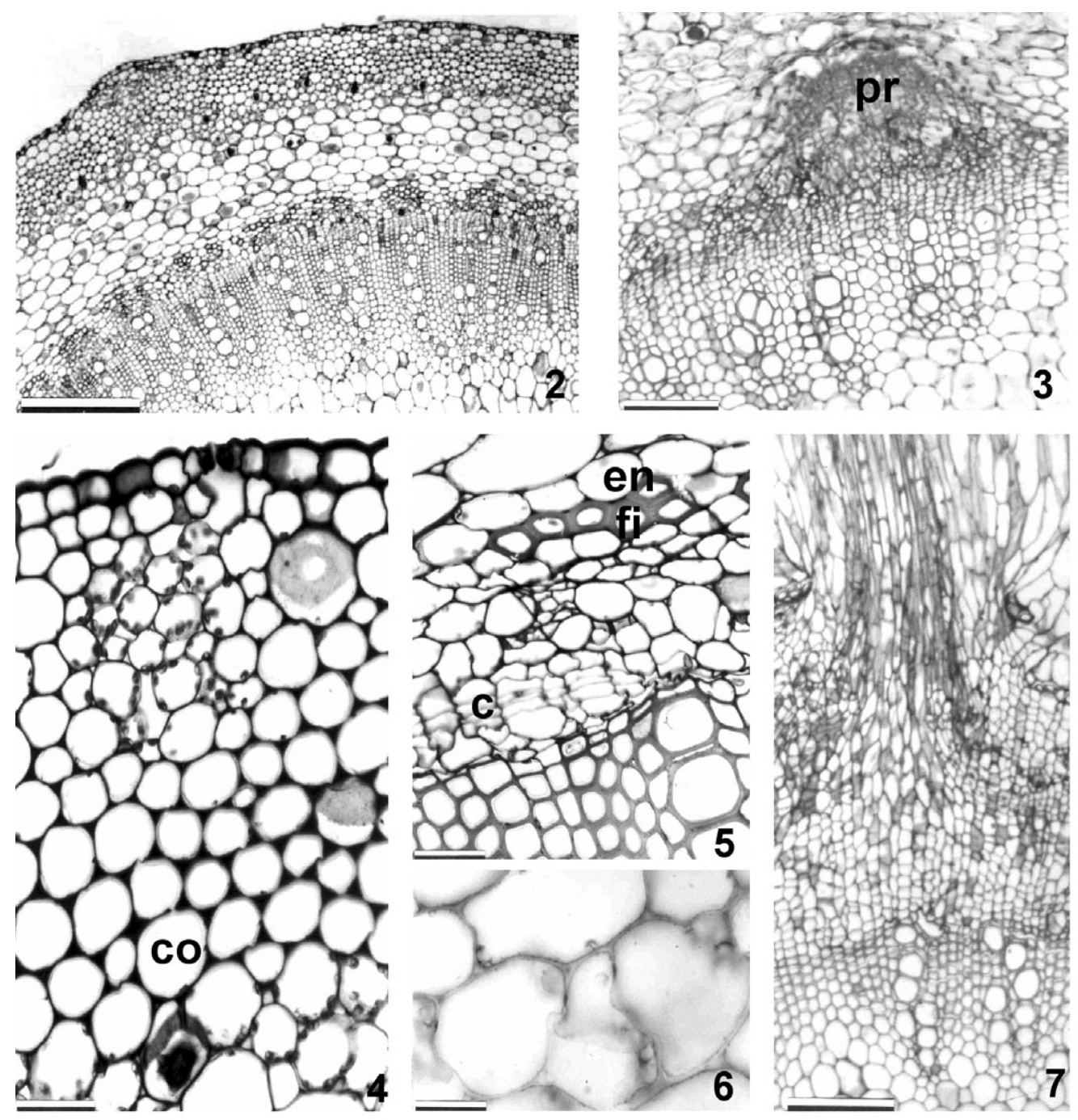

Figuras 2 a 7. Secções transversais de estacas caulinares de Odontonema strictum. 2. Estaca antes do tratamento (I0), (barra $=50 \mu \mathrm{m}) ; 3$. Estaca após 12 dias de experimento (I5), evidenciando uma raiz adventícia em formação (barra $=200 \mu \mathrm{m}) ; 4$. Detalhe da epiderme e córtex $(\mathrm{I} 0),($ barra $=50 \mu \mathrm{m}) ; \mathbf{5}$. Detalhe da região periférica do cilindro central (I5), (barra $=50 \mu \mathrm{m}) ; 6$. Detalhe da endoderme, (barra $=20 \mu \mathrm{m})$; 7. Região de conexão de uma raiz adventícia como o caule (I6), (barra $=50 \mu \mathrm{m}$. (pr) primórdio de raiz, (en) endoderme, (c) câmbio, (seta) estria de Caspary, (fi) fibras, (co) colênquima 
Após 12 dias do plantio (I4), foi observado na região nodal do caule de $O$. strictum a formação dos primórdios radiciais. A maior atividade mitótica ocorre na região externa do floema primário, indicando que a provável origem das raízes laterais é no periciclo ou no floema (Figura 3). Esse fato concorda com as observações de ESAU (1974), que registra que a origem das raízes adventícias geralmente é endógena, formando-se junto aos tecidos vasculares, crescendo através dos tecidos localizados ao redor do seu ponto de origem.

Em estacas herbáceas, cujos tecidos apresentam, na sua maioria, parede celular primária e não lignificada, as raízes adventícias não encontram barreiras estruturais para o seu desenvolvimento, o que pode explicar em parte a facilidade de enraizamento desta espécie (WHITE \& LOVELL, 1984; HARTMANN et al. 2002). As fibras pericíclicas, único tecido com parede lignificada, não são contínuas e nem tão pouco formam feixes bem desenvolvidos, o que poderia acarretar num obstáculo para o desenvolvimento das raízes.

No intervalo I6 (18 dias do plantio), as raízes laterais já encontravam-se totalmente formadas (Figura 7), ocorrendo, inclusive, a conexão do sistema vascular da raiz lateral com o sistema da estaca.

A origem de raízes laterais é variada e está relacionada com vários fatores, sendo um evento complexo, envolvendo a reativação de divisões celulares (MOREIRA et al., 2000). Existem dois padrões de formação de raízes adventícias, um através do desenvolvimento direto da raiz a partir dos tecidos caulinares e, outro, que consiste num processo indireto, com formação de calos antecedendo a formação das raízes (ALTAMURA, 1996). Em estacas herbáceas é comum a formação de raízes adventícias pelo processo direto, onde essas se formam a partir dos tecidos vasculares, mais precisamente do câmbio (WHITE \& LOVELL 1984; DAVIS et al. 1989; FERREIRA et al. 2001). Entretanto, isto depende do tipo de planta e da técnica de propagação. A formação de raízes adventícias, a partir das células floemáticas, como observado em Odontonema strictum, também foi descrita para outras espécies como Lycopersicum, Cucurbita e algumas variedades de Phaseolus (HARTMANN et al. 2002). A participação dos tecidos vasculares na formação das raízes adventícias, está relacionada com a conexão da raiz recém formada com o tecido vascular já existente, para garantir o processo de translocação para a nova planta que está surgindo (MOREIRA et al., 2000).

\section{CONCLUSÕES}

1. Odontonema strictum Kuntze pode ser considerada uma espécie de fácil enraizamento;

2. Tanto vermiculita como pó de casca de coco se mostraram substratos ideais para o enraizamento de Odontonema strictum.

3. Um dos fatores a proporcionar a facilidade de enraizamento de Odontonema strictum é o reduzido crescimento de tecidos mecânicos na região periférica do cilindro central das estacas caulinares.

\section{REFERÊNCIAS BIBLIOGRÁFICAS}

ALTAMURA, M. M. Root histogenisis in herbaceous and woody explants cultured in vitro. A critical review. Agronomie, Paris, v. 16, p. 589-602. 1996.

DAVIS, T. D.; HAISSIG, B. F. \& SANKHLA, N. Adventitious root formation. Portland Oregon: Dioscorides Press, 1989. $315 \mathrm{p}$.

ESAU, K. Anatomia das plantas com sementes. São Paulo: Edgard Blücher. 1974. 293p.

FEDER, N. \& O'BRIEN, T. P. Plant microtechnique: some principples and new methods. American Journal of Botany, v. 55, p. 123-142, 1968.

FERREIRA, G. G. A.; ZUFFELLATO-RIBAS, K. C.; CARPANEZZI, A. A.; TAVARES, F. R.; BOEGER, M. R. T. \& KOEHLER, H.. Enraizamento de Sapium glandulatum (Vell.) Pax. pela aplicação de ácido indol butírico e ácido bórico. Leandra, Rio de Janeiro, v. 16, p. 11-16, 2001.

HARTMANN, H. T.; KESTER D. E.; DAVIS JR., F. T. et al. Plant Propagation: principles and practices. $7 \mathrm{ed}$. New York: Englewood Clipps/Prentice Hall, 2002. 880p.

JOHANSEN, D.A. Plant Microtechnique. New York: Mc Graw Hill Book, 1940. 523 p.

LORENZI, H. \& SOUZA, H. M. de Plantas Ornamentais do Brasil: arbutivas, herbáceas e trepadeiras. Nova Odessa, São Paulo: Editora Plantarum, 2.ed., p. 352, 1999.

MOREIRA, F. M.; APPEZZATO-DA-GLÓRIA, B. \& ZAIDAN, L. B. P. Anatomical aspects of IBA-treated microcuttings of Gomphrena macrocephala St.-Hil. Brazilian Archives of Biology and Technology, Curitiba, v. 43, n. 2, p. 221-227, 2000.

O BRIEN, T. P.; FEDER, N. \& McCULLY, M. E. Polychromatic staining of plant cell walls by toluidine blue. O Protoplasma, New York, v. 59, n. 2, p. 368-373, 1965.

READ, P. E. \& YANG, G. Plant growth regulator effects on Rooting of forced softwood cuttings. Acta Horticulturae, Wageningen, v. 300, p. 197-200, 1991.

WHITE, J. \& LOVELL, P. H. The anatomy of root initiation in cuttings of Griselinia littoralis and Griselinia lucida. Annals of Botany, London, v. 54, p. 7-20. 1984. 